Brazilian Journal

of Chemical

ISSN 0104-6632

Engineering

\title{
SPOUTED BED DRYING OF Bauhinia forficata LINK EXTRACT: THE EFFECTS OF FEED ATOMIZER POSITION AND OPERATING CONDITIONS ON EQUIPMENT PERFORMANCE AND PRODUCT PROPERTIES
}

\author{
C. R. F. Souza and W. P. Oliveira ${ }^{*}$ \\ Faculdade de Ciências Farmacêuticas de Ribeirão Preto/USP, Phone: + (55) (16) 602-4185, \\ Fax + (55) (16) 633-1941, Avenida do Café S/N., 14040-903, Ribeirão Preto - SP, Brazil \\ E-mail: wpoliv@fcfrp.usp.br
}

(Received: October 20, 2004 ; Accepted: February 12, 2005)

\begin{abstract}
In this paper the effects of feed atomizer position and operating conditions on equipment performance (accumulation rate, product recovery, elutriation and thermal efficiency) and product properties (moisture content, size distribution, flavonoid degradation and flow properties) during spouted bed drying of Bauhinia forficata Link extract are evaluated. The parameters studied were the position of the atomizer system (top spray or bottom spray), the inlet temperature of the spouting gas $(80$ and $150 \mathrm{oC})$ and the feed mass flow rate of concentrated extract relative to the evaporation capacity of the dryer, $\mathrm{W}_{\mathrm{s}} / \mathrm{W}_{\max }$ (15 to $100 \%)$. Higher accumulation rate values were obtained with the atomizer placed at the bottom of the bed. In this configuration, the accumulation rate increases with the increase in the $\mathrm{W}_{\mathrm{s}} / \mathrm{W}_{\max }$ ratio. The best drying performance was obtained for the top spray configuration.

Keywords: Drying; Spouted bed; Accumulation rate; Product properties; Bauhinia forficata link.
\end{abstract}

\section{INTRODUCTION}

Drying of liquids and pastes in spouted beds with inert bodies has been presented as an alternative to spray drying in an attempt to obtain high-quality powdered products at a low cost (Cunha et al., 2000). According to Barret and Fane (1990), this technique involves spouting a bed of inert bodies with warm air and spraying liquid material into the bed; coating the bodies with a thin film. The warm air dries the film, which then becomes friable and fractures due to the attrition produced by the colliding bodies. This fractured film is removed with the exit air to be collected as the product and the film-free bodies are recycled by the spouted bed to be recoated. The process has two components: drying of the layer of liquid material followed by removal of the dried film. One of these stages will be rate-limiting; although in practical systems the rate of film removal must be greater than or equal to the material feed rate.

In the literature it is pointed out that there is a maximum drying capacity for the spouted bed drying of pastes and suspensions, since higher feed flow rates produce a bed collapse. The product properties and the conditions of stable operation; which result in the removal of solids without agglomeration of the inert particles, are dependent on system configuration and several operating parameters such as the flow

*To whom correspondence should be addressed 
rate of the liquid material and of the drying gas and the physical and chemical properties of the solid and liquid materials to be dried (Spitzner-Neto et al., 2002; Maialle et al., 2002; Souza and Oliveira, 2002; Daleffe and Freire, 2004).

In this paper the effects of feed atomizer position and operating conditions on equipment performance and product properties during spouted bed drying of Bauhinia forficata Link extracts, are evaluated. The tree Bauhinia forficata is a member of the family Caesalpiniaceae, commonly known as pata de vaca and unha de vaca (Brazil); Brazilian orchid tree (English); and pezuña de vaca and pesña de vaca (Spanish). It has been widely used in Brazilian folk medicine in the treatment of diabetes. In Brazilian herbal medicine, the Bauhinia species have been referred to as "vegetable insulin" (Yeh et al., 2003).

\section{MATERIALS AND METHODS}

\section{Materials}

The extract was prepared with dried and powdered Bauhinia forficata Link leaves with a mean diameter of $0.3 \mathrm{~mm}$. This material was purchased from the Santa Rosa Farm, located in Jundiaí, São Paulo State, Brazil. This material was characterized by loss on drying, extractable matter and total of flavonoids, used as a chemical marker in the thermal degradation studies.

Ethyl acetate, methanol, acetone, aluminum chloride, ethanol and chloridric acid were acquired from Synth; hexametilenetetramine (Vetec), dehydrated quercetin
(Sigma-Aldrich) and colloidal silicon dioxide (Tixosil $333^{\circledR}$ Rhodia) were used as reagents and standard materials. Teflon beads with a mean diameter of 5.45 $\mathrm{mm}$, a density of $2160 \mathrm{~kg} / \mathrm{m}^{3}$ and a concave-cylindrical shape were used as inert material.

\section{Equipment}

The dryer consists of a conical base with an internal $40^{\circ}$ angle and an inlet orifice diameter of 33 $\mathrm{mm}$. A cylindrical column with a diameter of $150 \mathrm{~mm}$ and a height of $400 \mathrm{~mm}$ is connected to the conical base of the dryer. The upper part of the equipment is composed of another cone and a cyclone. All parts are made of stainless steel. The main components of the system are a 7.5 HP blower, a flow meter, an electric heater and a temperature controller. The extract feed system consists of a double fluid atomizer with internal mixing $(0.8 \mathrm{~mm}$ hole $)$, a peristaltic pump and an air compressor. The acquisition data system is composed of a data board PCL 711-S ADVANTECH and a temperature reading board PCL 789D, linked to a PC running the software LABTECH. Thermocouples, pressure transducers and a psychrometer were employed in the equipment instrumentation. Figure 1 shows a schematic diagram of the experimental rig. The other devices used were stirrers, an air circulating oven, analytical balances, spectrophotometer UV-VIS HP 8453 running the software HP Chem-Station ${ }^{\circledR}$, a scanning electronic microscope DSM 960 Zeiss and an optical microscope Olympus ${ }^{\circledR}$ BX60MIV connected to an image analysis system Image Pro-plus ${ }^{\circledR} 4.5$.

\begin{tabular}{|c|}
\hline \multicolumn{1}{|c|}{ CAPTION } \\
01 - BLOWER \\
02 - VALVES \\
03 - AIR HEATER \\
04 - FLOW METER \\
05 - SPOUTED BED \\
06 - ATOMIZER \\
07 - PRESSURE TAPS \\
08 - THERMOCOUPLES
\end{tabular}
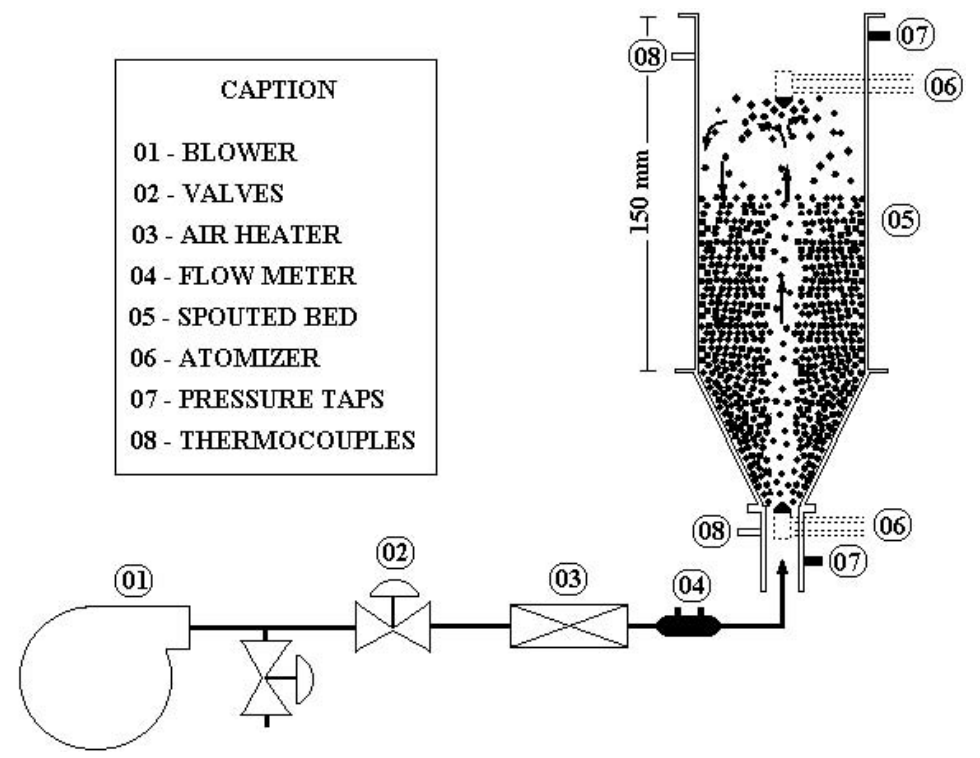

Figure 1: Schematic diagram of the experimental rig. 


\section{Experimental Methods}

- Preparation of the Extract Solution:

Dried and powdered Bauhinia forficata leaves were placed in an ethanol:water solution (70:30 in weight) at a temperature of $50^{\circ} \mathrm{C}$ and stirred for 1 hour in an extraction system composed of a jacketed vessel with stirring and temperature control. The extract was filtered under vacuum and concentrated three times in a rotary evaporator. Its density, solids and total flavonoid contents were determined.

\section{Drying Process}

The concentrated extracts added with colloidal silicon dioxide ( $80 \%$ of the solids content) were dried in the spouted bed. The operation started with the introduction of a given load of inert material into the equipment. Spouting occurred when air was injected at the base of the bed. When the spout was established the inlet air was heated to the desired temperature. Once the desired temperature was reached, feeding of the concentrated extract at a preset flow rate and of the atomizing air was started. Measurements of the outlet gas temperature, $\mathrm{T}_{\mathrm{g} 0}$, were taken at regular intervals in order to detect the moment when the process attained the steady state $( \pm$ 15 minutes). Once the steady state was attained, samples of the dried extract were removed during 30 minutes. The samples were used for physical and chemical characterization of the dried product. To evaluate system performance, the inlet and outlet spouting gas temperature and humidity; the temperature and humidity of the environment; the temperature of the external surface of the thermal insulating, $\mathrm{T}_{\mathrm{w}}$; the product mass accumulated in the inert material and in the drying chamber and the product collected by the cyclone were measured during the operation.

The parameters studied were position of the feed atomizer (at the top of the fountain - top spray - and at the base of the bed - bottom spray); the inlet gas temperature, $\mathrm{T}_{\mathrm{gi}}\left(80\right.$ and $\left.150^{\circ} \mathrm{C}\right)$, and the ratio of the mass feed flow rate of the concentrated extract to the evaporation capacity of the dryer, $\mathrm{W}_{\mathrm{s}} / \mathrm{W}_{\max }(15,45$, 75 and $100 \%$ ). Results on the evaporation capacity of this dryer were presented elsewhere (Souza and Oliveira, 2002). The mass flow rate of the drying gas was maintained at $0.0340 \mathrm{~kg} / \mathrm{s}\left(\mathrm{Q} / \mathrm{Q}_{\mathrm{ms}}=1.4\right)$. The atomizing air feed flow rate was fixed at $15 \mathrm{~L} / \mathrm{min}$ with a pressure of $147.1 \mathrm{kPa}$.
Physical and Chemical Properties of the Vegetable Matter the Extract Solution and the Product

- Loss on Drying (WHO, 1998):

Samples of the vegetable matter were maintained in an oven at $102 \pm 1{ }^{\circ} \mathrm{C}$ until constant mass was obtained. The result was expressed in weight percentage by averaging three measurements.

- Extractable Matter:

A solution 1:100 grams of vegetable matter in water (dry basis) was heated to boiling and filtered after cooling. Samples of $20.0 \mathrm{~g}$ of the filtrate were removed and put in the oven at $102^{\circ} \pm 1^{\circ} \mathrm{C}$ until constant mass was obtained. The extracted matter was calculated as the percentage ratio of the mass of dry residue to the mass of vegetable matter by averaging three measurements.

- Total Flavonoid Content:

This was evaluated by spectrophotometry (UVVIS), using predefined masses of samples. The procedure includes hydrolysis of the glycosides, followed by flavonoid extraction with ethyl acetate and color development with a solution of aluminum chloride (Kulevanova et al., 2000). Absorbance was measured at $425 \mathrm{~nm}$ after 30 minutes. The percentage of total flavonoid (TF), expressed as quercetin, was calculated with equation (1) by averaging three measurements.

$$
\mathrm{TF}=\frac{\mathrm{A} \mathrm{Fd}}{611.7 \mathrm{C}_{\mathrm{s}}}
$$

- Flavonoid Degradation Rate, D:

It was defined as the percentage ratio of the difference between the flavonoid content in the concentrated extract solution and in the dried extract to the flavonoid content in the concentrated extract solution.

- Residual Moisture Content in the Dried Extracts, Xp:

Samples of $2.0 \mathrm{~g}$ of dried extracts were maintained in an air circulating oven at $102 \pm 1^{\circ} \mathrm{C}$, until constant mass was obtained (Brazilian Pharmacopoeia, 1988).

- Size Distribution, Morphology and Flow Properties of the Dried Product:

The size distribution was determined by optical microscopy and image analysis with a magnification of 50 times. Product morphology was evaluated by electronic scanning microscopy with a magnification of 3000 times. The flow properties (loosely packed and tapped bulk densities, the Hausner ratio and the compressibility index) were estimated according to procedures presented in Prista et al. (1995). 


\section{Evaluation of Dryer Performance}

Dryer performance was evaluated through determination of the mass accumulation rate in the bed, Ac; elutriation rate, E; product recovery rate, R; and the thermal efficiency of the dryer, $\eta$.

The accumulation rate in the bed, Ac; the product recovery rate, $\mathrm{R}$, and the elutriation rate, $\mathrm{E}$, were estimated by mass balance in the dryer using equations (2) to (4):

$$
\begin{aligned}
& \mathrm{Ac}=\frac{\left(\mathrm{M}_{\mathrm{f}}-\mathrm{M}_{\mathrm{i}}\right)(1-\mathrm{Xp})}{\mathrm{W}_{\mathrm{s}} \mathrm{C}_{\mathrm{s}} \theta} 100 \\
& \mathrm{R}=\frac{\mathrm{Mc}(1-\mathrm{Xp})}{\mathrm{W}_{\mathrm{s}} \mathrm{C}_{\mathrm{s}} \theta} 100 \\
& \mathrm{E}=100\left(\mathrm{~W}_{\mathrm{s}} \mathrm{C}_{\mathrm{s}} \theta(1-\mathrm{Ac}-\mathrm{R})\right)
\end{aligned}
$$

For all experiments, the total solids mass introduced in to the dryer, $\mathrm{W}_{\mathrm{s}} \mathrm{C}_{\mathrm{s}} \theta$; the total mass collected by the cyclone, Mc, and the total bed mass at the beginning, $\mathrm{Mi}$, and the end of the process, Mf, were measured. Under all operating conditions studied, the internal parts of the dryer were clean for both positions of the atomization system, i.e., without any powder accumulation on the walls except for the inert material. Samples of inert bodies were photographed at the end of the drying to record the accumulation phenomenon. Measurements of the inlet and outlet spouting gas temperature and humidity, the temperature and humidity of the environment and the temperature of the external

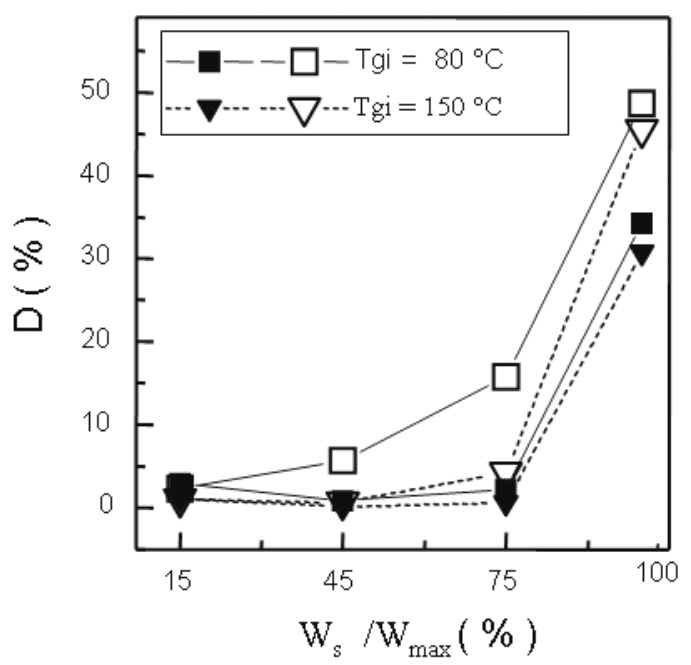

Figure 2: Flavonoid degradation as a function of the operating parameters and feed atomizer position. surface of the thermal insulating, $\mathrm{T}_{\mathrm{w}}$, were also taken to estimate thermal efficiency of the dryer, $\eta$, defined by equation (5) (Souza, 2003):

$$
\eta=1-\frac{\overline{\mathrm{h}} \mathrm{A}_{\mathrm{is}}\left(\mathrm{T}_{\mathrm{w}}-\mathrm{T}_{\mathrm{amb}}\right)}{\mathrm{W}_{\mathrm{g}} \mathrm{C}_{\mathrm{pg}}\left(\mathrm{T}_{\mathrm{gi}}-\mathrm{T}_{\mathrm{go}}\right)}
$$

\section{RESULTS AND DISCUSSION}

\section{Physical and Chemical Properties of the Vegetable Matter, the Extract Solution and the Product}

The plant material had a moisture content (loss on drying) of $9.5 \pm 0.2(\% \mathrm{~g} / \mathrm{g})$, extractable matter of $21.4 \pm 0.01(\% \mathrm{~g} / \mathrm{g})$ and a total flavonoid content of $1.6 \pm$ $0.2(\% \mathrm{~g} / \mathrm{g})$. The results obtained for the concentrated extract were a density of $0.95 \pm 0.01\left(\mathrm{~g} / \mathrm{cm}^{3}\right)$, a solids content of $8.05 \pm 0.06(\mathrm{~g} / \mathrm{g})$ and a total flavonoid content of $13.1 \pm 0.03$ ( $\% \mathrm{~g} / \mathrm{g}$, dry basis).

Figures 2 to 4 show the experimental results on the flavonoid degradation rate, $\mathrm{D}$; the moisture content, $X p$, and the mean product diameter, $d_{p}$, as a function of the processing parameters and feed atomizer position (solid: top spray; hollow: bottom spray). Statistical analyses of the results of the flavonoid degradation rate showed the variable $\mathrm{W}_{\mathrm{s}} / \mathrm{W}_{\max }$ had a significant effect at $\alpha=0.05$. $\mathrm{W}_{\mathrm{s}} / \mathrm{W}_{\max }$ values higher than $75 \%$ resulted in an increase in the degradation rate, D. At $\mathrm{T}_{\mathrm{gi}}=80^{\circ} \mathrm{C}$, higher $\mathrm{D}$ values were obtained for the bottom spray configuration.

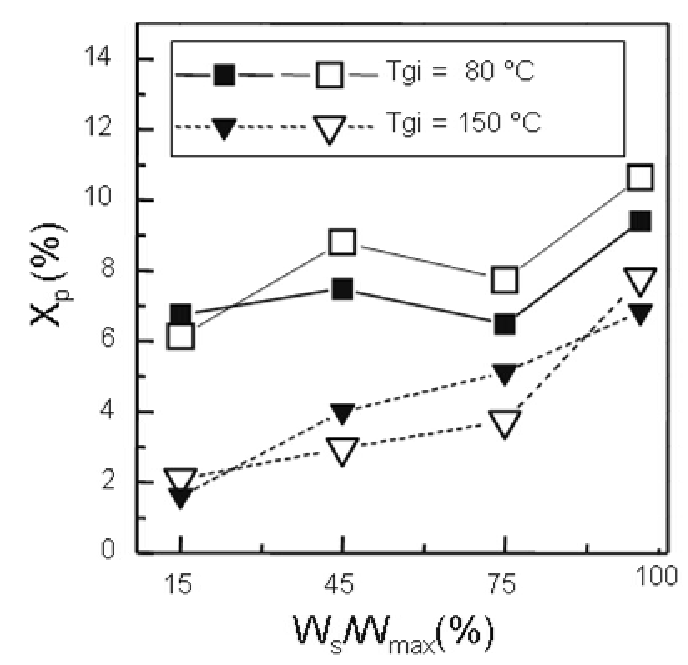

Figure 3: Moisture content as a function of the operating parameters and feed atomizer position. 


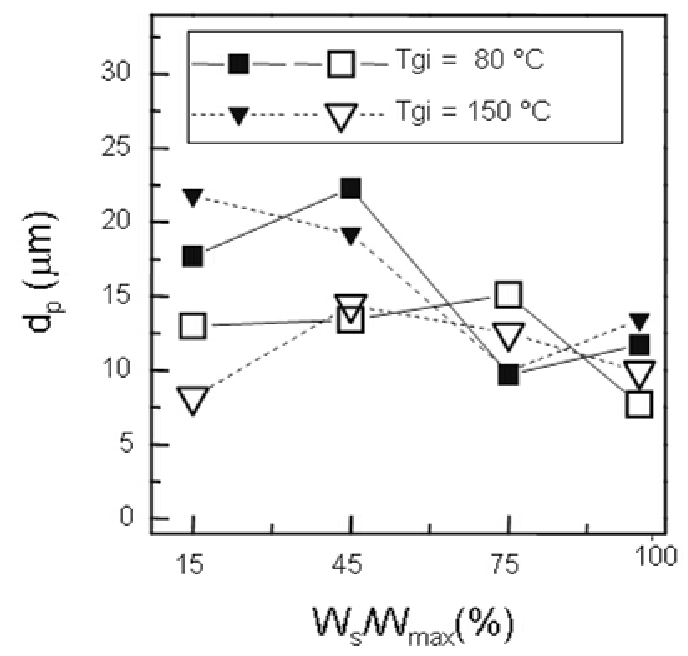

Figure 4: Mean product diameter as a function of the operating parameters and feed atomizer position.

Figure 3 shows a tendency for product moisture to increase with $\mathrm{W}_{\mathrm{s}} / \mathrm{W}_{\max }$ and to decrease with the inlet gas temperature. The position of the feed atomizer did not have a significant effect on $X_{p}$. The upper limit for moisture content in the dried extracts stated by the Brazilian Pharmacopoeia (1998) is $\leq 4 \%$. Considering this limit as a criterion of comparison between the dryer configurations studied it can be concluded that the drying operation can be successfully conducted until $\mathrm{W}_{\mathrm{s}} / \mathrm{W}_{\max }$ is $75 \%$ for the bottom spray feed system and $45 \%$ for the top spray configuration. Figure 4 shows that products with a higher mean diameter were obtained for small values of the $\mathrm{W}_{s} / \mathrm{W}_{\max }$ ratio and the top spray configuration. For small $\mathrm{W}_{\mathrm{s}} / \mathrm{W}_{\max }$ values, moisture removal from the atomized material is very fast. Thus, a significant amount of the atomized material did not reach the surface of the inert bodies and therefore, experienced less attrition the bed (similarly to the spray drying). With the increase in the $\mathrm{W}_{\mathrm{s}} / \mathrm{W}_{\max }$ ratio, a significant amount of the atomized material initially coats the inert material and drying occurs as it passes through the zones of the spouted bed with the predominance of attrition. The temperature did not have a significant effect on the mean particle diameter.

Figure 5 shows typical photomicrographs of the dried product, magnified 3000 times. In this figure irregular flakes-shaped particles, more characteristic of the bottom spray configuration, can be observed.

Evaluation of the flow properties of the dried product show small values for the loosely packed and tapped bulk densities, respectively between 0.19 to $0.29 \mathrm{~g} / \mathrm{cm}^{3}$ and 0.35 to $0.48 \mathrm{~g} / \mathrm{cm}^{3}$. Values from 1.61 to 1.92 were found for the Hausner ratio. According to Prista et al. (1995) and Jong et al. (1999), Hausner ratio values higher than 1.25 indicate a cohesive or fairly free-flowing tendency. The compressibility index showed values from 38 to $48 \%$, indicative of a powder with poor compression characteristics. These results are related to the irregular shape, small particle diameter and characteristic of the drying aid.
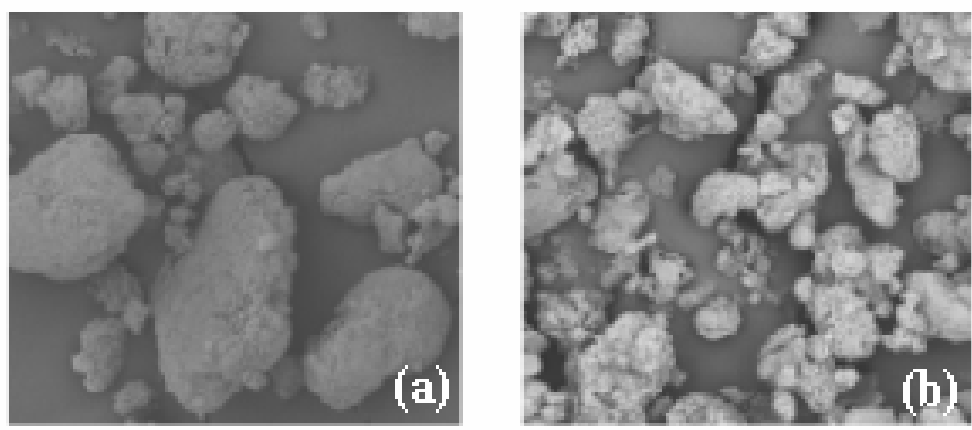

Figure 5: Typical photomicrographs of the dried extract, magnified 3000 times, $\mathrm{W}_{\mathrm{s}} / \mathrm{W}_{\max }=15 \%, \mathrm{~T}_{\mathrm{gi}}=150^{\circ} \mathrm{C}$, (a) top spray and (b) bottom spray. 


\section{Dryer Performance}

Figure 6 shows graphs of the accumulation rate during drying as a function of the operating parameters and feed atomizer positions (solid: top spray; hollow: bottom spray). In this figure, a small product accumulation for the top spray configuration can be observed for $\mathrm{W}_{\mathrm{s}} / \mathrm{W}_{\max }$ values up to $75 \%$. The accumulation rate tends to increase for $\mathrm{W}_{\mathrm{s}} / \mathrm{W}_{\max }$ higher than $75 \%$, however, with lower values than those for the bottom spray atomization. In the top spray feeding, the fountain is the first zone to be wetted. Compared with the atomization at the bottom of the dryer, the inert material receives a smaller quantity of the atomized material due to the spray drying effect. The probability that the film of moist material on the inert surfaces will be dried and removed in the first stages of the operation is high. As a consequence, the coat layer formed on the surfaces of the inert bodies is reduced, facilitating moisture removal as the material passes through the annular zone. Thus, when this material reaches the central zone, the coated layer has been completely dried and is easily removed by the attrition in that zone, returning to the fountain practically without any atomized material. Increasing the $\mathrm{W}_{\mathrm{s}} / \mathrm{W}_{\max }$ ratio to more than $75 \%$, an increase in the accumulation rate can be observed. This behavior is a consequence of the large amount of material atomized on the inert material, resulting in an increase in coat film thickness and in the humidity inside the dryer. When the inert material returns to the atomizing zone, its surface is partially coated, receiving a new layer of atomized material, contributing to product accumulation (Markowski, 1992). The accumulation rate increased with the increase in $\mathrm{W}_{\mathrm{s}} / \mathrm{W}_{\max }$, for both temperatures studied. When fed in at the base of the dryer, the inert material leaves the atomization zone totally or partially coated with a layer of the atomized material. If this layer has been dried or is brittle enough and if the particle velocity is adequate, collisions between the particles and/or between the particles and dryer walls remove the coated layer completely. From the fountain, the particles return to the annulus. If the coat layer has not been removed, its moisture content will be reduced in the heart of the annulus. The dried material can now take two directions: return to the wetting zone (atomization) or leave the system. Returning to the atomizing zone partially coated, the inert bodies receive a new layer of the atomized material, resulting in an increase in the thickness of the coating layer with processing time. The accumulation rate tends to decrease with the increase in inlet gas temperature. Photographs of the inert material after drying support the discussion above (see Figure 7). This figure shows, qualitatively, an increase in the coating layer on particle surfaces with the increase in the $\mathrm{W}_{\mathrm{s}} / \mathrm{W}_{\max }$ ratio, a phenomenon that is more pronounced for the bottom spray configuration.

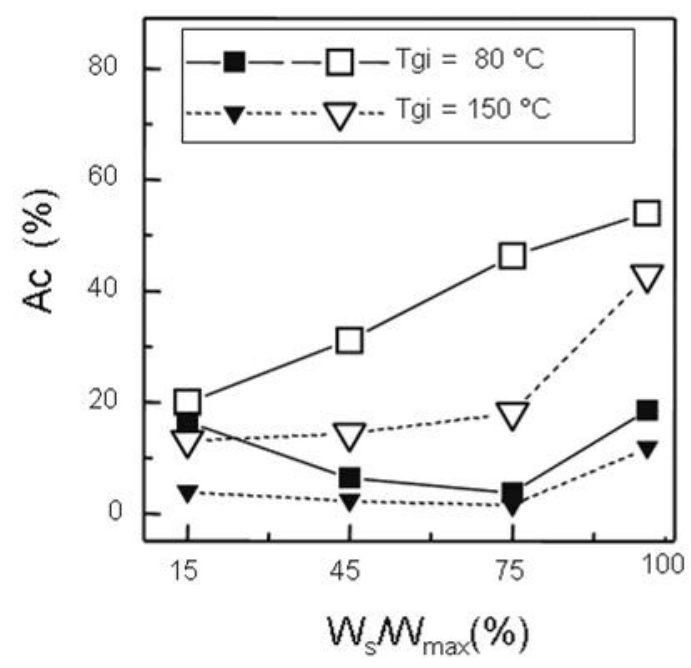

Figure 6: Accumulation rate as a function of the operating parameters and feed atomizer position. 


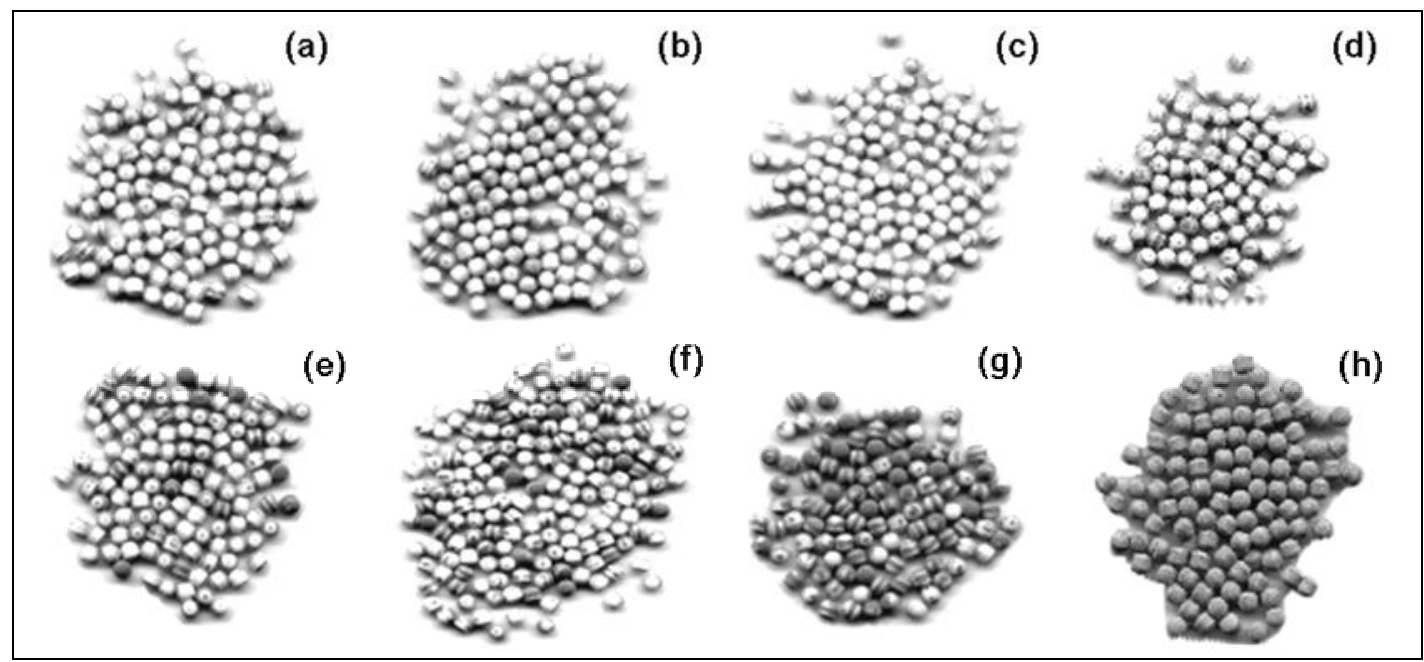

Figure 7: Teflon beads after the drying operation as a function of atomizer position and $\mathrm{W}_{\mathrm{s}} / \mathrm{W}_{\max }$ for $\mathrm{T}_{\mathrm{gi}}=150{ }^{\circ} \mathrm{C}$ : (a) to (d) top spray, $\mathrm{W}_{\mathrm{s}} / \mathrm{W}_{\max }=15,45,75$ and $100 \%$; (e) to (h) bottom spray, $\mathrm{W}_{\mathrm{s}} / \mathrm{W}_{\max }=15,45,75$ and $100 \%$.

Figure 8 shows graphs of product recovery as a function of the operating parameters and feed atomizer position (solid: top spray; hollow: bottom spray). Recovery rates between 50 and $85 \%$ of the solids fed in to the system were obtained for the top spray configuration and for the inlet gas temperature of $150{ }^{\circ} \mathrm{C}$. Values between 25 and $68 \%$ were obtained for feeding at the base of the dryer. The elevation of the inlet gas temperature results in an increase in the thermal energy supplied to the system, producing an increase in the evaporation velocity of the liquid in the extractive composition feding to the dryer. Consequently, the relative gas humidity in the bed is reduced and products with a lower residual moisture content are obtained. These factors reduced the tendency towards agglomeration of the feed material

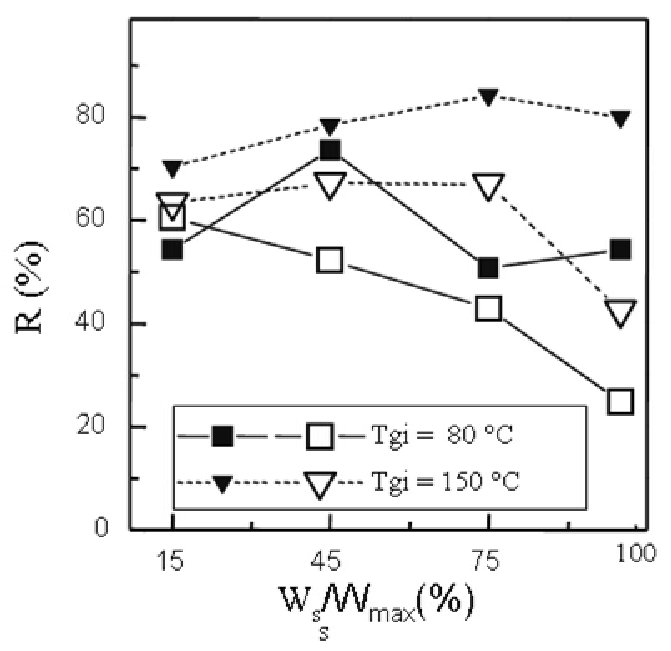

Figure 8: Product recovery rate as a function of the operating parameters and feed atomizer position. and inert particles as well as agglomeration on dryer walls, resulting in an increasing recovery rate.

Figure 9 shows the results for elutriation rate as a function of the operating parameters and feed atomizer position (solid: top spray; hollow: bottom spray). The elutriation rate showed a tendency to decrease with the increase in $\mathrm{W}_{\mathrm{s}} / \mathrm{W}_{\max }$, for the temperature of $150{ }^{\circ} \mathrm{C}$.

Figure 10 shows the experimental results for thermal efficiency as a function of the operating parameters and feed atomizer position (solid: top spray; hollow: bottom spray). The specific heat, $\mathrm{C}_{\mathrm{pg}}$, was estimated at mean temperature of the dryer. The coefficient of heat transfer between the external surface of the thermal insulation and the environment of $11.6 \mathrm{~W} /\left(\mathrm{m}^{2} . \mathrm{K}\right)$ was adopted. As expected, thermal efficiency increases with $\mathrm{W}_{s} / \mathrm{W}_{\max }$ and decreases with temperature of the drying gas.

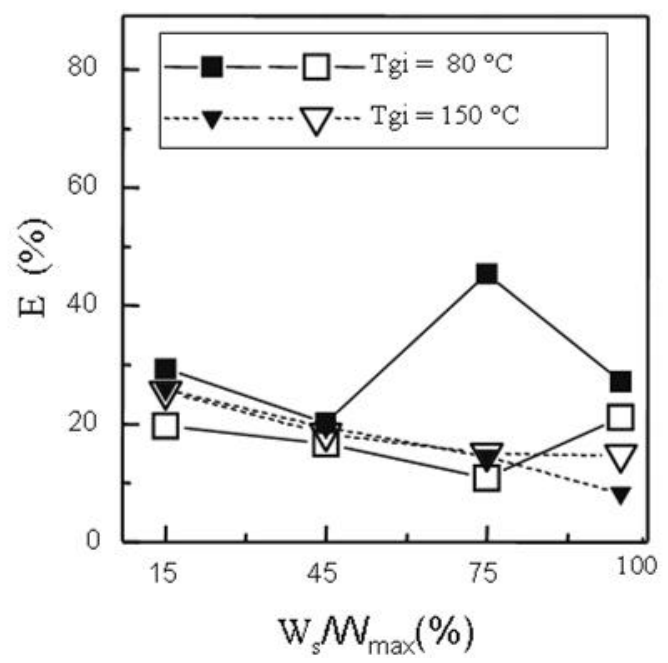

Figure 9: Elutriation rate as a function of the operating parameters and feed atomizer position. 


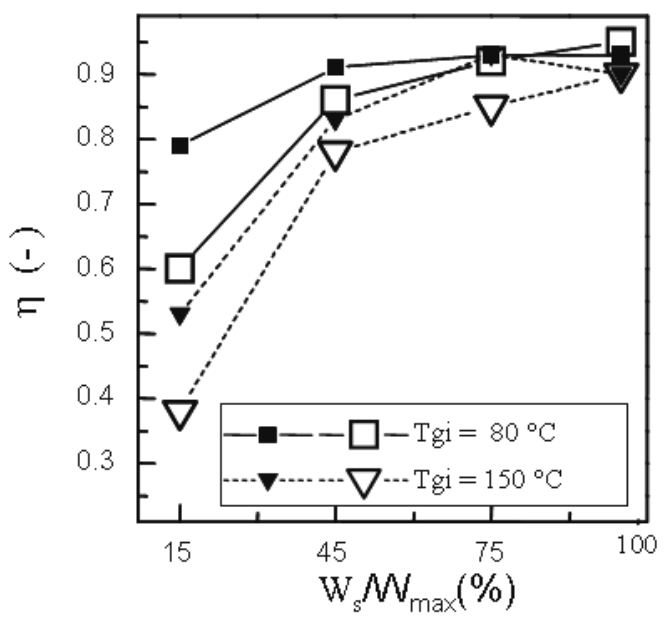

Figure 10: Thermal efficiency as a function of the operating parameters and feed atomizer position.

\section{CONCLUSIONS}

The spouted bed drying of materials with high thermal sensitivity and rich in sugar and resins, such as medicinal plant extracts, is technically feasible. A common problem during the drying of these materials is the adhesion phenomenon, intrinsically associated with product degradation, low product recovery and problems of dryer malfunctioning (Kudra, 2003). This problem can be minimized by the correct selection of a drying aid and drying conditions. Product properties and dryer performance are dependent on the operating conditions and the system configuration as well. This study showed the best system performance when feeding the liquid material in at the top of the fountain, leading to a stable operation with a low accumulation of the product in the bed. With this configuration, correct selection of the operating parameters can result in a product with the desired physical and chemical properties, in this work a dried extract with moisture content of less than $4 \%$ and low thermal degradation. The optimum conditions found were $\mathrm{T}_{\mathrm{gi}}=150{ }^{\circ} \mathrm{C}, \mathrm{W}_{\mathrm{s}} / \mathrm{W}_{\max }=45 \%$ and the top spray feeding system.

\section{ACKNOWLEDGEMENT}

The authors thank FAPESP for the fellowship awarded the first author and for the financial support (Proc. 00/12397-2 and 01/10140-7).

\section{NOMENCLATURE}

A absorbance UA

Ac accumulation rate

$\mathrm{A}_{\text {is }} \quad$ thermal insulating surface area

$\% \mathrm{~g} / \mathrm{g}$

$\mathrm{C}_{\mathrm{pg}} \quad$ specific heat of the drying gas

$\mathrm{C}_{\mathrm{s}} \quad$ solids content

D flavonoid degradation rate

E elutriation rate

$\mathrm{Fd}$ dilution factor

$\overline{\mathrm{h}} \quad$ mean heat transfer coefficient

Mc recovered mass

Mf final mass of the dryer

$\mathrm{Mi} \quad$ initial mass of the dryer

Q gas flow rate

$\mathrm{Q}_{\mathrm{ms}} \quad$ gas flow rate at minimum spouting

$\mathrm{R} \quad$ product recovery rate

$\mathrm{T}_{\text {amb }} \quad$ room temperature

TF flavonoid content expressed as quercetin

$\mathrm{T}_{\mathrm{gi}} \quad$ inlet gas temperature

$\mathrm{T}_{\mathrm{go}} \quad$ outlet gas temperature

$\mathrm{T}_{\mathrm{w}}$ temperature of the external insulating surface

Xp product moisture content \%

$\mathrm{W}_{\max }$ evaporation capacity of the $\mathrm{g} / \mathrm{s}$ dryer

Wg mass flow rate of the spouting g/s gas

$\mathrm{W}_{\mathrm{s}}$ mass flow rate of the feed $\mathrm{g} / \mathrm{s}$ composition 


\section{Greek Symbols}

$\begin{array}{ll}\alpha & \text { significance level } \\ \theta & \text { processing time } \\ \eta & \text { thermal efficiency of the dryer }\end{array}$

$(-)$

$\mathrm{s}$

$(-)$

\section{REFERENCES}

Barret, N. and Fane, A., Drying Liquid Materials in a Spouted Bed, Drying' 89, New York, Hemisphere Publ, Co., B, 415 (1990).

Brazilian Pharmacopoeia, $3^{\text {rd }}$ ed. São Paulo: Andrei (1988) (in Portuguese).

Cunha, R.L., Maialle, K.G. and Menegalli, F.C., Evaluation of the Drying Process in Spouted Bed and Spout Fluidized Bed of Xanthan Gum: Focus on Product Quality, Powder Tech., 107, 234 (2000).

Daleffe, R.V. and Freire, J.T., Analysis of the Fluiddynamic Behavior of Fluidized and Vibrofluidized Bed Containing Glycerol, Braz. J. Chem. Eng., $21, \mathrm{~N}^{\mathrm{o}} 1,35$ (2004).

Jong, J.A.H., Hoffmann, A.C. and Finkers, H.J., Properly Determine Powder Flowability to Maximize Plant Output, Chem. Eng. Prog., 95, № 4, 25 (1999).

Kudra, T., Sticky Region in Drying: Definition and Identification, Drying Tech., 21, № 8, 1457 (2003).

Kulevanova, S., Stefova, M. and Stafilov, T., Determination of Total Flavonoids and Quercetin

in Hyperici herba and its Aqueous, AqueousEthanolic and Oil Extracts, Acta Pharm., 50, 29 (2000).

Maialle, K.G., Cunha, R. and Menegalli, F.C., Drying of Suspensions in a Spout-fluidized Bed: Study of Critical Conditions of Operation, Proc. $13^{\text {th }}$ Int. Drying Symp., A, 555, China (2002).

Markowski, A.S., Drying Characteristics in a Jetspouted Bed Dryer, Can. J. Chem. Eng., 70, № 5, 938 (1992).

Spitzner-Neto, P.I., Cunha, F.O. and Freire, J.T., Effect of the Presence of Paste in a Conical Spouted Bed Dryer with Continuous Feeding, Drying Tech., 20, № 4\&5, 789 (2002).

Prista, L.N., Alves, A.C. and Morgado, R., Pharmaceutical Tech., vol II, $4^{\text {th }}$ ed., Fundation Calouste Gulbenkian, (1995) (in Portuguese).

Souza, C.R.F. and Oliveira, W.P., Comparative Study of the Evaporation Capacity of the Conventional and Jet Spouted Bed Dryers for Liquid Materials, Proc. $13^{\text {th }}$ Int. Drying Symp., B, 808 China (2002).

Souza, C.R.F., Comparative Study of the Production of Dried Extract of Bauhinia forficata Link by the Spray-dryer and the Spouted Bed Processes, (M.Sc.Thesis) USP, 180p (2003) (in Portuguese).

WHO, Quality Control Methods for Medicinal Plant Materials, Geneve, Switzerland (1998).

Yeh, G.Y., Eisemberg, D.M., Kaptchuk, T.J. and Phillips R.S., Systematic Review of Herbs and Dietary Supplements for Glycemic Control in Diabetes, Diabetes Care, 26, № 4, 1277 (2003). 